Received: March 21, 2017

Accepted: April 03, 2017

Published: April 17, 2017

\section{Burden and Depression among Caregivers of Hemodial- ysis Patients}

\author{
Dayana Shakya*, Jyoti Tuladhar ${ }^{1}$ and Sabitra Poudel ${ }^{1}$ \\ ${ }^{1}$ Lecturer,B.Sc. Nursing Program, Kathmandu Medical College, Sinamangal, Kathmandu, \\ Nepal
}

*Corresponding author: Dayana Shakya, Lecturer, B. Sc. Nursing Program, Kathmandu Medical College, Sinamangal, Kathmandu, Nepal,Tel:+977 9849511461; E-mail: dianashakya@gmail.com

\section{Abstract}

\subsection{Introduction}

End stage renal disease affects almost all aspects of life of the patients and their caregivers. The caregiver role is stressful and demanding but is often neglected, especially in developing countries like Nepal. Hence, this study attempts to assess the burden on caregivers and find out their liability for developing depression.

\subsection{Methods}

Cross sectional, descriptive study design was used. Purposive sampling was used to collect data from all patients undergoing hemodialysis at Human Organ Transplant Center. Face to face interview was conducted with the caregivers. Semi structured questionnaires were used to measure socio-demographic and dialysis related variables whereas standard tools Zarit Burden Interview (ZBI) and Beck's Depression Inventory (BDI) were used to measure burden and depression. Analysis was done using inferential statistics.

\subsection{Findings}

The study found $60 \%$ of the caregivers to be $<40$ years with mean age as $37.24 \pm 13.2$ years. Majority of caregivers were married, more than half were females and employed and $70 \%$ had $<10$ years of formal education. Almost half of the caregivers had moderate to severe burden with around $17 \%$ having severe burden. Also, 35\% of the caregivers had moderate to severe depression. Analysis with inferential statistics showed that burden increased with increasing age, decreasing education and decreasing social support. Marital status, socioeconomic status and relationship to patient were also found to affect burden. Moreover, caregiver burden was significantly positively associated with depression.

\subsection{Conclusion}

Caregivers of hemodialysis patients are facing significant burden and more than one third are moderate to severely depressed. Interventions to provide appropriate social support services and improve psychological conditions of caregivers is of urgent and paramount importance.

\subsection{Keywords}

Hemodialysis; Burden; Depression; Caregivers; Chronic kidney disease; End stage renal disease

\section{Introduction}

With the rapid rise in number of patients with End Stage Renal Disease (ESRD) and those with comorbid conditions receiving renal replacement therapies, combined with the increasing demands of the 21st century, burden on the caregivers have increased even more than in the past days [1]. These caregivers not only have to sustain their living and maintain their quality of life, they also have to take care of their chronically ill family member. Moreover, as the chronic kidney disease patients are usually middle to old aged adults, their caregivers (primarily found to be spouses) are equally aged partners, many of whom have their own physical ailments, lack community connections, and have limited financial reserves [2]. This is even more true when the caregivers are parents. And when the caregivers are children for older patients, though the caregivers are younger, their burden is high due to the increasing demands of the bread winning population.

In Nepal, where most people cannot afford paid caregivers and rely on family members to take care of the sick, the topic of burden of caregivers is more significant. The caregivers, sometimes out of love and sometimes out of obligation, take care of their chronic patients despite all odds. Furthermore, when the 
disease of the patients is chronic (like ESRD with dialysis), debilitating, expensive yet temporary, the burden for caregivers peak to no bounds, especially in a resource limited country like Nepal. Even in this context, studies in Nepal, focussing on the needs and burden of the caregivers of hemodialysis patients are scarce.

It is important to understand caregiver characteristics and explore the relationship of their level of burden with quality of life parameters and psychosocial aspect of patients. This will optimize the use of support and interventional measures and help reduce negative effect on the caregivers' lives [1].

The stress of treatment and disease burden due to lifelong dialysis is inevitable on the patients and the entire family $[1,3]$; especially when the patient is the head of the household. The prevalence of moderate to severe depression in caregivers of hemodialysis patients was found to be $33.4 \%$ in a study done in Pakistan [4]. However in another study, the depressive symptoms were observed in $43.82 \%$ of the caregivers, even more than in the patients (40.74\%) [5]. Low income status, marital status and unemployment were found to be positively associated with depression [4]. In Nepal, as caregivers are mostly unpaid family members, the chances of exhaustion of caregiving and depression may be common.

As the studies looking into the depressive symptoms of caregivers of hemodialysis patient are scarce, the researcher attempts to assess the burden and depression on caregivers of HD patients.

\section{Methods}

\subsection{Design and Study Population}

Descriptive, cross sectional study design was adopted to assess the burden of the caregiver of hemodialysis patients and find out the association of caregiver burden with depression. Data was collected in the hemodialysis ward of Human Organ Transplant Center (HOTC), Bhaktapur. The caregivers were met outside the hemodialysis ward when the patient was undergoing hemodialysis.

\subsection{Data Collection Tool and Method}

A total of 164 eligible caregivers of patients taking maintenance hemodialysis from the dialysis wards of Human Organ Transplant Center (HOTC) were taken in the study. Separate face to face interview was carried out with the caregivers in the waiting area after taking written informed consent from them. The primary caregiver was followed up for interview for three times and if unavailable were excluded from the study.

Caregivers of age 18 and more who had been taking care of the patient for at least 3 months were included in the study. Caregivers of patients returning to hemodialysis after failure of renal transplant and caregivers of HIV and Hepatitis B positive patients undergoing hemodialysis were excluded from the study.

Caregivers answered questions related to demographic variables (of patients and caregivers) and hemodialysis related variables (frequency, duration, presence of comorbidities, dialysis access and perceived social support). Caregiver burden was measured by Zarit Burden Inventory (ZBI) and depression was mea- sured by using Beck Depression Inventory (BDI)

$\mathrm{ZBI}$ is a 22-item questionnaire with a five-item response set ranging from "never" to "nearly always." Zero to 20 points mean little or no burden, $21-40$ points mean mild to moderate burden, 41-60 points mean moderate to severe burden, and 61-88 points mean severe burden. ZBI has been successfully used in many studies that determine the burden of care of patients undergoing dialysis. The validity and reliability of ZBI has been measured by previous studies. The crohnbach's alpha was found to be 0.93 and the intra-class correlation coefficient for the test-retest reliability of the Zarit burden score was 0.89 [6].

The Beck Depression Inventory (BDI) is a validated 21-item questionnaire assessing the probability of depression, with scores ranging from 0 to 63 ; a score of $\geq 21$ is highly suggestive of clinical depression. The reliability scores of BDI was found to be 0.88 in the Nepalese context [7].

Pretesting of the data collection tools for its feasibility and appropriateness was done in Aarogya Foundation, Pulchowk among $10 \%$ of the estimated sample size.

Before collecting data, ethical clearance for the study was obtained from the Institutional Review Committee of Kathmandu Medical College. Written informed consent was taken from each respondent before data collection. The respondents were given full authority to withdraw from the study without fear or explanation any time during the investigation. Confidentiality was maintained throughout the study by omitting the name or any other identity of the respondents as well as by conducting the interview separately. Obtained data was used for research purpose only. The interview lasted about 30-45 minutes.

Among the 240 patients undergoing maintenance hemodialysis at HOTC, respondents meeting the eligibility criteria were 202. Twenty-two patients had started dialysis less than 3 months ago, 4 caregivers were less than 18 years of age, 5 lived alone and 7 had died. From the 202 eligible caregiver, data could not be collected from a total of 38 respondents. Among the 38 patients, 19 said nobody from their family could come because they cannot leave their daily wages job or it's too far and expensive for them to come. Ten patients were very irregular and could not be contacted, 6 caregivers could not be met with more than three follow ups and 3 patients refused to bring their caregivers to participate in the study as they were coming alone for dialysis.

\subsection{Statistical Analysis}

Mann Whitney U and Kruskal Wallis $\mathrm{H}$ tests were used for inferential statistics. The dependant variables were kept continuous while using inferential statistics, Correlation between two continuous variables, burden and depression was verified using Pearson's correlation coefficient. The level of significance was considered at 5\% with $p \leq 0.05$ and $95 \%$ confidence interval.

\subsection{Result}

The distribution of patients and caregivers according to the sociodemographic variables is shown in (Table 1). The mean age of patients was found to be 46.56 years and that of the caregivers was found to be 37.24 years. Around $65 \%$ of patients were males, 
one third of patients as well as caregivers had secondary level education and around one third patients had service to earn their living. Majority of the caregivers were spouses (40.9\%) or children (31.7\%).

Majority of the patients (74.4\%) underwent dialysis twice a week. The median duration of dialysis was 14 months. Comorbidities present in the patients undergoing dialysis were diabetes, hypertension, heart diseases, gout and stroke, hypertension being the most common (76.2\%). Almost all patients (97.6\%) used AV fistula for venous access. More than half of the patients $(53.7 \%)$ reported that they perceived social support from their family and near ones. Almost half of the caregivers (49.4\%) reported moderate to severe burden with a very small $3.7 \%$ reporting little or no burden (Table 2). None of the socio-demographic parameters of the patients were found to have any association with caregiver burden. However, in terms of caregivers, it is seen that burden is high in caregivers above age 40, having less than 10 years of formal education and in those who perceive lack of social support. Caregiver burden is also significantly associated with marital status, socioeconomic status and relationship to the patient. However, duration of dialysis, frequency of dialysis, venous access and comorbid illness were not found to have any significant association with caregiver burden.

Depression score was found to increase as the burden increased and statistically significant association was found between caregiver burden and depression (Table 3). Caregiver burden was found to have significant positive correlation with depression (Table 4).

\section{Discussion}

\subsection{Level of Burden among Caregiver}

The assessment of burden among the caregivers found the mean burden score to be $46.99 \pm 14.6$. The categorization of burden revealed $4 \%$ with little or no burden, $30 \%$ with mild to moderate burden, $49 \%$ with moderate to severe burden and $17 \%$ with severe burden. Moderate to severe burden was also reported by another study done in Saudi Arabia [8]. A contradicting result was found by Rioux et al, which showed low burden perceived by the caregivers. The author has discussed that this result may be because the caregivers have underestimated the overall burden [9].

\subsection{Socio-demographic Variables of Caregivers and Care- giver Burden}

The caregiver burden was found to be significantly higher in caregivers above the age of 40 . This may be because it is difficult for the older caregivers to travel and manage treatment for their patients as compared to the younger caregivers. However, this finding is contradicted in literature as the caregiver burden was found to be significantly higher in younger than in older caregivers $[8,10]$. In more developed countries like Turkey and Saudi Arabia where these researches are carried out, the facilities of transportation and health care may have made it easier for the older caregivers in providing health care to their patients.

Caregivers with higher education ( $>10$ years of formal edu-
Table 1 Socio-demographic Variables of Hemodialysis Patients and their Caregivers $\mathrm{n}_{1}=\mathrm{n}_{2}=164$

\begin{tabular}{|c|c|c|}
\hline \multirow[t]{2}{*}{$\begin{array}{c}\text { Socio-demographic } \\
\text { Variables }\end{array}$} & $\begin{array}{l}\text { Patients } \\
\left(\mathrm{n}_{1}\right)\end{array}$ & $\begin{array}{l}\text { Caregivers } \\
\left(\mathrm{n}_{2}\right)\end{array}$ \\
\hline & $\begin{array}{l}\text { Frequency } \\
(\%)\end{array}$ & $\begin{array}{l}\text { Frequency } \\
(\%)\end{array}$ \\
\hline \multicolumn{3}{|l|}{ Age } \\
\hline Less than 40 & $57(34.8)$ & $99(60.4)$ \\
\hline $41-50$ & $43(26.2)$ & $37(22.6)$ \\
\hline $51-60$ & $36(22)$ & $20(12.2)$ \\
\hline More than 60 & $28(17.1)$ & $8(4.9)$ \\
\hline Mean age \pm SD & $46.56(15.4)$ & $37.24(13.2)$ \\
\hline \multicolumn{3}{|l|}{ Sex Distribution } \\
\hline Male & $107(65.2)$ & $72(43.9)$ \\
\hline Female & $57(34.8)$ & $92(56.1)$ \\
\hline \multicolumn{3}{|l|}{ Educational level } \\
\hline Illiterate & $39(23.8)$ & $34(20.7)$ \\
\hline Primary level & $37(22.6)$ & $29(17.7)$ \\
\hline Lower secondary & $13(7.9)$ & $12(7.3)$ \\
\hline Secondary level & $42(25.6)$ & $40(24.4)$ \\
\hline $\begin{array}{l}\text { Higher secondary } \\
\text { level }\end{array}$ & $17(10.4)$ & $30(18.3)$ \\
\hline Graduation & $15(9.1)$ & $16(9.8)$ \\
\hline $\begin{array}{l}\text { Post-graduation } \\
\text { and above }\end{array}$ & $1(0.6)$ & $3(1.8)$ \\
\hline \multicolumn{3}{|l|}{ Occupation } \\
\hline Agriculture & $34(20.7)$ & $26(15.9)$ \\
\hline Service & $56(34.1)$ & $28(17.1)$ \\
\hline Business & $18(11)$ & $38(23.2)$ \\
\hline Housewives & $19(11.6)$ & $38(23.2)$ \\
\hline Retired & $9(5.5)$ & $4(2.4)$ \\
\hline Student & $13(7.9)$ & $22(13.4)$ \\
\hline Others & $15(9.1)$ & $8(4.9)$ \\
\hline \multicolumn{3}{|l|}{ Marital status } \\
\hline Married & $129(78.8)$ & $124(75.6)$ \\
\hline Single & $28(17.1)$ & $38(23.2)$ \\
\hline Widowed & $7(4.3)$ & $2(1.2)$ \\
\hline $\begin{array}{l}\text { Income } \\
\text { (Median) }\end{array}$ & & $\begin{array}{c}20000 \\
(4000-250000)\end{array}$ \\
\hline \multicolumn{3}{|l|}{ Relation } \\
\hline Spouse & - & $67(40.9)$ \\
\hline Children & - & $52(31.7)$ \\
\hline Parents & - & $16(9.8)$ \\
\hline Siblings & - & $14(8.5)$ \\
\hline Children in law & - & $6(3.7)$ \\
\hline Grandchildren & - & $5(3)$ \\
\hline Others & - & $4(2.4)$ \\
\hline
\end{tabular}


Table 2 Burden among Caregivers of Hemodialysis Patients $n=164$

\begin{tabular}{|l|l|l|}
\hline $\begin{array}{l}\text { Caregiver } \\
\text { Burden }\end{array}$ & Frequency & Percentage \\
\hline $\begin{array}{l}\text { Little or } \\
\text { no Burden }\end{array}$ & 6 & 3.7 \\
\hline $\begin{array}{l}\text { Mild to } \\
\text { moderate burden }\end{array}$ & 49 & 29.9 \\
\hline $\begin{array}{l}\text { Moderate to } \\
\text { severe burden }\end{array}$ & 81 & 49.4 \\
\hline $\begin{array}{l}\text { Severe } \\
\text { burden }\end{array}$ & 28 & 17.1 \\
\hline $\begin{array}{l}\text { Mean } \\
\text { Burden } \\
\text { Score }\end{array}$ & \multicolumn{2}{|c|}{$46.99 \pm$} \\
\hline
\end{tabular}

Table 3 Association between Caregiver Burden and Depression $n=164$

\begin{tabular}{|l|l|}
\hline $\begin{array}{l}\text { Caregiver } \\
\text { Burden }\end{array}$ & Depression \\
\cline { 2 - 2 } & Median \\
\hline $\begin{array}{l}\text { Little or no } \\
\text { burden }\end{array}$ & 2 \\
\hline $\begin{array}{l}\text { Mild to } \\
\text { moderate } \\
\text { burden }\end{array}$ & 6 \\
\hline $\begin{array}{l}\text { Moderate to } \\
\text { severe } \\
\text { burden }\end{array}$ & 18 \\
\hline $\begin{array}{l}\text { Severe } \\
\text { burden }\end{array}$ & 29 \\
\hline \#p value & $<0.05^{*}$ \\
\hline $\begin{array}{l}\text { \#Kruskal } \\
\text { Wallis H test } \\
\text { *p significant at } \leq 0.05 \\
\text { level of } \\
\text { significance }\end{array}$
\end{tabular}

Table 4 Correlation between Caregiver Burden and Depression $n=164$

\begin{tabular}{|c|c|c|}
\hline & Depression & $\begin{array}{c}\mathrm{p} \\
\text { value }\end{array}$ \\
\hline $\begin{array}{l}\text { Caregiver } \\
\text { Burden }\end{array}$ & $r=0.625^{\wedge}$ & $<0.05^{*}$ \\
\hline
\end{tabular}

cation) were found to have significantly less burden. This finding is in accordance to a study done in Saudi Arabia which showed statistically significant negative correlation between caregiver burden and caregiver education [8]. It is a general consideration that increased education and awareness about a disease condition may make it more tolerable for patients and their families [4]. Educated people can reach out to health resources, understand the disease process better and cope better with adverse situations which may be the reason of lesser burden in more educated population. However, another study done in Turkey in 2013 showed caregiver burden to be statistically significantly higher in caregivers with higher education than in those with lower education [10]. This contradiction may be because educated caregivers are more well versed with the complications of the disease, causing them more stress and more burden.

More than half of the caregivers (56\%) were found to be employed with many among them (23\%) doing their own small business. More than half (23\%) of the unemployed caregivers (44\%) were housewives. This shows that in the Nepalese context, where there is no policy for health insurance, the caregivers have to earn their living when the primary bread winners of the family (adult males) fall sick. However, Belasco AG and Sesso R found an almost equal distribution of caregivers who were employed (34\%), unemployed (33\%) and homemakers (33\%) [1]. On the other hand, Bayoumi found $60 \%$ of the caregivers to be unemployed or housewives and $40 \%$ to be employed [8]. Conversely, Mollaoglu et al. found $80.3 \%$ of the caregivers to be housewives and that profession had no impact on caregiver burden [10].

This study also revealed that there is significant difference in burden among caregivers in terms of marriage, the widowed scoring the highest median score in burden followed by married and then single. Usually the widows and widowers have nobody to share their sorrows with and often feel more burdened. At the same time, the married caregivers have not only the patient but also the whole family to look after and hence have higher amount of burden scores. In contrast to this finding was the finding of Mollaoglu in which caregiver burden was found to be statistically significantly higher in single than in married caregivers [11].

The estimation of socioeconomic status showed that most of the caregivers were in the upper lower class (45.7\%) and lower middle class (38.4\%). There was significant difference in caregiver burden in terms of socioeconomic status. The economic crisis in this category of people seems to have increased the burden in the caregivers significantly.

Among the caregivers in this study, $41 \%$ were found to be spouses, $32 \%$ to be children, $10 \%$ to be parents, $9 \%$ siblings, $4 \%$ children in laws and $3 \%$ were even grandchildren. This finding is supported by studies done by Belasco AG and Sesso R and Gaugler et al $[1,12]$. Yet another study revealed $65 \%$ of caregivers to be spouses and also showed that spouse were found to have lower mean value of caregiver burden as compared to other relations [10]. In contrary, this study showed significant difference in caregiver burden in terms of relationship, with spouses and parents having higher median values of caregiver burden as compared to other relations. This may be because in the Nepalese context, the children live together with the parents and the spouses are 
mainly housewives, thus they are more directly involved in the care of their patients.

The median duration of dialysis was calculated to be 14 months in this study as compared to $\mathbf{5 1 . 5}$ months in a study done in Turkey [13]. This may be because the center is relatively newly established. Another study done in Pakistan revealed that 57.6\% had undergone dialysis for more than 8 months [14]. The same study also showed that duration of dialysis had a negative correlation with quality of life in the patients. However, the duration of dialysis was not found to be associated with caregiver burden in this study. But it has been proven during the qualitative analysis of a study that, as the disease worsens, new problems arise in the patient and the caregiver burden inevitably aggravates by time, eventually leading to burnout [15].

Majority of the patients (74.4\%) were found to have 2 cycles of dialysis a week followed by $20.7 \%$ having 3 cycles a week and $4.3 \%$ having one cycle a week. Similar results were shown by a study done by Anees in which $77.6 \%$ had 2 cycles of dialysis per week [14].

Besides having diabetes and hypertension as the causes of ESRD, other comorbid conditions found in patients undergoing dialysis were angina, congestive heart failure, arthritis, respiratory illness, neurologic diseases and liver diseases. No significant differences in burden scores were found according to the nature of the comorbid conditions. Similar finding was shown in the study done by Suri et al where the presence or absence of comorbidity was not found to be associated with caregiver burden [16].

\subsection{Association of Caregiver Burden and Depression}

In the present study, 35\% of the caregivers were found to have moderate to extreme depression. It is worth noting that among these, $13.4 \%$ had severe and $2.4 \%$ had extreme depression. This finding is comparable to the findings of the study done by Rioux et al in Canada in which depression was found to be present in both patients (47\%) and caregivers (25\%) and 14\% of patients and $9 \%$ of caregivers had fulfilled criteria for severe depression [9]. Depressive symptoms and anxiety were also observed in $43.3 \%$ and $27.5 \%$ of the caregivers respectively in a study done in 142 pairs of hemodialysis patients and their caregivers [13].

In this study, the caregiver burden was highly significantly associated with depression with significant positive correlation between the two $(r=0.625)$. Hence, when the caregiver burden increased, the depressive symptoms in caregivers increased as well. A study analogous to this has shown that higher perceived burden was significantly associated with higher BDI scores [16]. It was observed that the patients $(40.74 \%)$ as well as the primary caregivers (43.82\%) had depressive symptoms. A positive association $(r=0.43, \mathrm{P}<0.001)$ was found between self-perceived burden and the presence of depressive symptoms in patients also [17].

\section{Conclusion}

Majority of the caregivers of hemodialysis patients are facing burden of caring for a chronic patient. The caregiver burden was found to be more in caregivers above 40 years of age, having less than 10 years of formal education and perceiving less social support. Moreover, caregiver burden was also found to be affected by marital status and socioeconomic status but not affected by the frequency of dialysis, duration of disease, comorbidity or venous access. However, caregiver burden was found to be significantly associated and correlated with depression, depression increasing significantly with increasing burden.

Hence, chronic kidney disease and dialysis places an increased demand on the caregivers of these patients when ongoing lifestyle adjustments become necessary as the disease complicates. In the Nepalese context, where there is no government health insurance policies, less educated people and lesser facilities of developing countries, the burden of caregivers are not given sufficient attention. This results in more caregiver burnout and exhaustion. Interventions to provide appropriate social support services and improve psychological conditions of caregivers and patients with ESRD should be planned and evaluated, particularly in high-risk groups.

\section{Acknowledgement}

The researchers acknowledge University Grants Commission (UGC) for awarding a mini research grant to this study.This article is in accordance to the final report submitted to UGC. The researchers are also thankful to Human Organ Transplant Center for granting permission to collect data.

\section{Declaration}

\subsection{Conflict of Interest}

A mini research grant (665 USD) was received for this study as a motivation to the researchers. Ethical Approval: Ethical approval for the study was taken from Institutional Review Committee of Kathmandu Medical College.

\section{References}

1. Belasco AG, Sesso R. Burden and quality of life of caregivers for hemodialysis patients. Am J Kidney Dis. 2002;39(4):805-812.

2. Cohen LM, Germain MJ. Caregiver burden and hemodialysis. Clin J Am Soc Nephrol. 2014;9(5):840-842.

3. Tong A, Sainsbury P, Craig JC. Support interventions for caregivers of people with chronic kidney disease: A systematic review. Nephrol Dial Transplant. 2008;23(12):3960-3965.

4. Saeed Z, Ahmad AM, Shakoor A, Ghafoor F, Kanwal S. Depression in patients on hemodialysis and their caregivers. Saudi J Kidney Dis Transpl. 2012;23(5):946-952.

5. Arechabala MC, Catoni MI, Palma E, Barrios S. Depression and self-perceived burden of care by hemodialysis patients and their caregivers. Rev Panam Salud Publica. 2011;30(1):7479.

6. Seng B, Luo $\mathrm{N}, \mathrm{Ng} \mathrm{W}$, et al. Validity and reliability of the zarit burden interview in assessing caregiving burden. Ann 
7. Kohrt B, Kunz R, Koirala N, Sharma V, Nepal M. Validation of the nepali version of beck depression inventory. Nepalese Journal of Psychiatry. 2001;2:123-30

8. Bayoumi MM. Subjective burden on family carers of hemodialysis patients. Open Journal of Nephrology. 2014;4(2):79-85.

9. Rioux JP, Narayanan R, Chan CT. Caregiver burden among nocturnal home hemodialysis patients. Hemodial Int. 2012;16(2):214-219.

10. Mollaoglu M, Kayatas M, Yurugen B. Effects on caregiver burden of education related to home care in patients undergoing hemodialysis. Hemodial Int. 2013;17(3):413-420.

11. Mollaoglu M. Perceived social support, anxiety and self care among patients receiving hemodialysis. Dialysis and Transplantation. 2006;35(3):144-155.

12. Gaugler J, Davey A, Pearlin L, Zarit S. Modeling caregiver adaptation over time, the longitudinal impact of behavioral problems. Physiology and Aging. 2000;15(3):437-450.
13. Celik G, Annagur BB, Yilmaz M, Demir T, Kara F. Are sleep and life quality of family caregivers affected as much as those of hemodialysis patients? Gen Hosp Psychiatry. 2012;34(5):518-524.

14. Anees M, Hameed F, Mumtaz A, Ibrahim M, Khan MNS. Dialysis-related factors affecting quality of life in patients on hemodialysis. Iran J Kidney Dis. 2011;5(1):9-14.

15. Gayomali C, Sutherland S, Finkelstein FO. The challenge for the caregiver of the patient with chronic kidney disease. Nephrol Dial Transplant. 2008;23(12):3749-3751.

16. Suri RS, Larive B, Garg AX, et al. Burden on caregivers as perceived by hemodialysis patients in the frequent hemodialysis network (fhn) trials. Nephrol Dial Transplant. 2011;26(7):2316-2322.

17. Arechabala MC, Catoni MI, Palma E, Barrios S. Depression and self-perceived burden of care by hemodialysis patients and their caregivers. Rev Panam Salud Publica. 2011;30:74-79. 